Case Report

\title{
A Painless Restricted Motion of the Thumb: What Etiology? About An Uncommon Tumor in Uncommon Localization
}

\author{
Naoufal Elghoul (D), Mohammed Benchakroun, Azzelarab Bennis, Omar Zaddoug, Ali Zine, \\ Mansour Tanane, and Abdeloihab Jaafar
}

Department of Orthopedic Surgery and Traumatology, Military Hospital Mohammed V (HMIMV), Faculty of Medicine and Pharmacy, University Mohammed V, BP 10100 Rabat, Morocco

Correspondence should be addressed to Naoufal Elghoul; naoufal.elghoul@gmail.com

Received 26 January 2020; Revised 1 March 2020; Accepted 3 March 2020; Published 31 May 2020

Academic Editor: Koichi Sairyo

Copyright (c) 2020 Naoufal Elghoul et al. This is an open access article distributed under the Creative Commons Attribution License, which permits unrestricted use, distribution, and reproduction in any medium, provided the original work is properly cited.

\begin{abstract}
Lipomas in fingers are rare and account for less than $1 \%$ of all cases. As a type of lipoma, the spindle cell lipoma is exceptional and it presents $1.5 \%$ of total adipocyte tumors. Moreover, its localization in the thumb is extremely rare. Only three cases have already been reported in adults; our case constitutes the fourth case, which is about a 61-year-old female who presented since 18 months a mass on the ulnar lateral aspect of the thumb. After clinical and radiological assessments, an entire excisional biopsy of the mass was performed. The histopathological analysis confirmed the spindle cell lipoma of the thumb. At the last follow-up of two years, the patient did well with no recurrence and no restricted motion of the thumb. So, although lipomas of the digit are rare, they should be considered a possible etiology of either painful or mechanic restricted motion of the digit.
\end{abstract}

\section{Introduction}

Lipomas account for approximately $16 \%$ of soft tissue mesenchymal tumors. However, they are rare in the hand and extremely rare in fingers that account for less than $1 \%$ of all cases [1]. Spindle cell lipoma is a type of lipoma that presents $1.5 \%$ of total adipocyte tumors [2]. The index and middle fingers were most commonly involved [3]. Therefore, its localization in the thumb is extremely rare [3-5]. Herein, we report a rare case of a variant of lipoma localized in the thumb.

\section{Case Presentation}

A 61-year-old female, maid, with no disease history, presented, since 18 months, a painless mass in the right thumb which increased slowly. The patient did not consult since it is not painful and does not bother her during physical activity. However, for the last two months, the mass started to bother her in her daily activities and it became a protruding mass; she consulted our orthopedic department. On admission, she was at good general health with no weight loss. At this visit, she reported a trauma history of the thumb two years ago. The clinical examination found a prominent mobile mass on the ulnar lateral aspect of the thumb with neither inflammatory changes nor a palpable pulse (Figure 1(a)). Passive mobility of the thumb was conserved. The neurovascular exam was normal. The plain anteroposterior radiograph of the digit was normal with no bone invasion. The ultrasound revealed a well-uniform low-echo mass measuring $45 \times 30 \times 20 \mathrm{~mm}$ on the ulnar lateral aspect of the thumb with no internal flow on Doppler, to be completed by magnetic resonance imaging for lesion characterization. Considering the patient's financial conditions, the magnetic resonance imaging was not performed. A few days later, the patient underwent surgery in which we performed an excisional biopsy of the mass of the thumb (Figure 1(b)). The postoperative was uneventful. One week later, the histopathological analysis showed a spindle cell lipoma of the thumb (Figures 1(c) and 1(d)). At the last follow-up of two years, the patient did well with no recurrence of the tumor and no restricted motion of the thumb. 


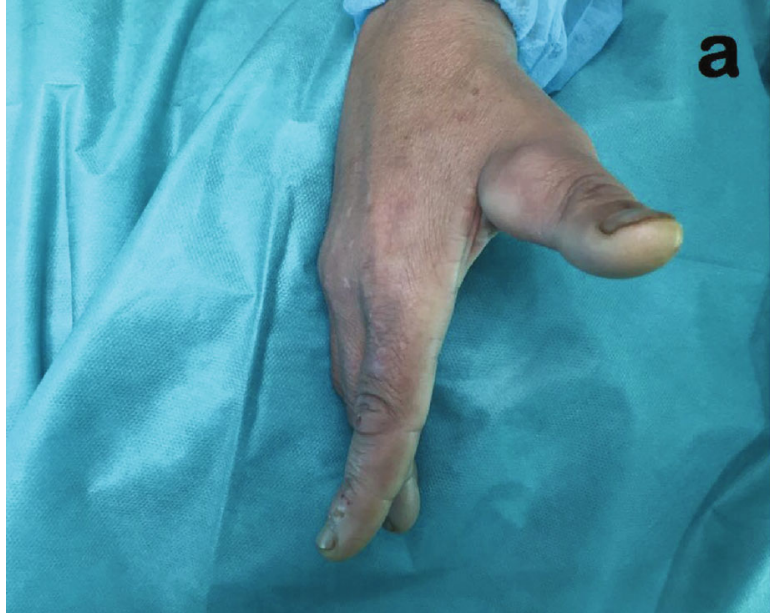

(a) Clinical aspect of the tumor at the right thumb

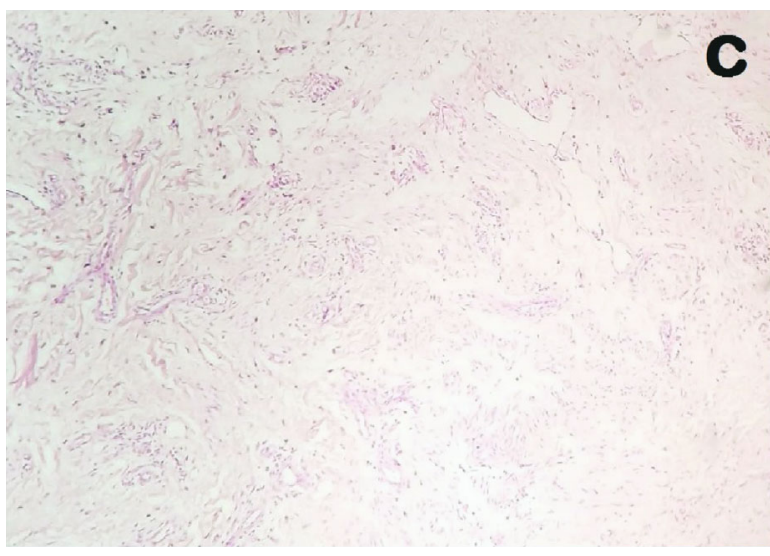

(c) Tumor with lobules and a spindle cells component $(\mathrm{HE} \times 100)$

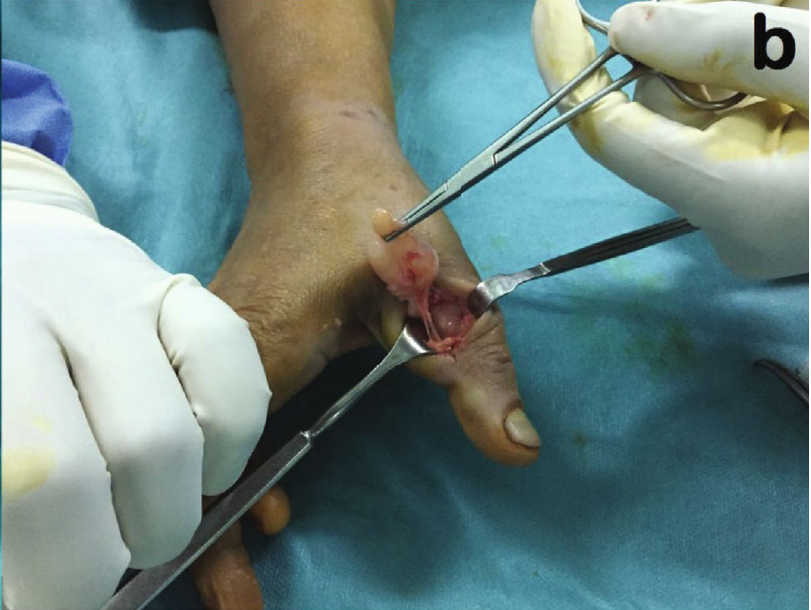

(b) Intraoperative aspect of the spindle cell lipoma in the thumb

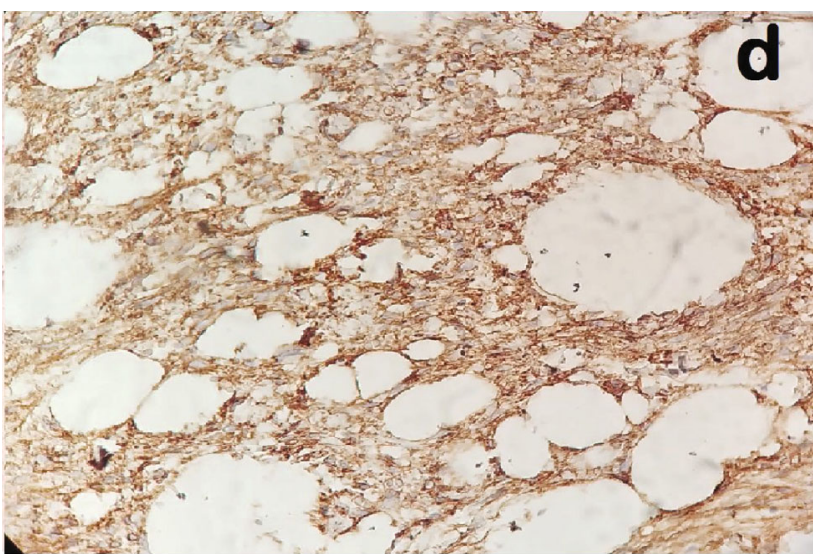

(d) Immunohistochemical study showed the expression for anti-CD34 antibodies

Figure 1

TABLe 1: The four cases of spindle cell lipoma in adults.

\begin{tabular}{|c|c|c|c|c|}
\hline Authors & Diagnosis & Localization & Age (year) & Gender \\
\hline El Rayes et al. [3] & Spindle cell lipoma & Thumb & 61 & Male \\
\hline Bhat et al. [4] & Spindle cell lipoma & Thumb & 30 & Female \\
\hline Ebisudani et al. [5] & Spindle cell lipoma & Thumb & 34 & Male \\
\hline Our case & Spindle cell lipoma & Thumb & 61 & Female \\
\hline
\end{tabular}

\section{Discussion}

The lipomas of the digit are rare. Furthermore, as a type of lipomas, the spindle cell lipoma is a rare tumor that is reported for the first time by Enzinger and Harvey in 1975 [6]. Its localization in the thumb is exceptional, and only three cases were reported. The first and second cases were two males with this tumor on the palmar aspect of the thumb. The third case was a female with a small tumor of the thumb $(10 \times 10 \mathrm{~mm})$. Therefore, our case was a female with spindle cell lipoma on the lateral aspect of the thumb measuring $45 \times 30 \mathrm{~mm}$ that restricted its motion. To our knowledge, this is the fourth reported case of spindle cell lipoma of the thumb in adults, and it is the second case in a woman (Table 1). The etiology and pathogenesis of this tumor are still undetermined. However, a history of trauma was found in almost cases. Also, in our case, a history of trauma of the thumb was reported before the appearance of the tumor. The differential diagnoses are important to know which are the well-differentiated sclerosing liposarcoma and the spindle cell liposarcoma [7]. Given that the spindle cell lipoma may be misdiagnosed with liposarcoma in this location, it should be kept in mind that it could appear also in this site. Clinically, most lipomas are asymptomatic.

However, patients are often uncomfortable with the limitation of mobility once they reach a significant size [8] 
as in our case. Imaging studies (computed tomography scan and magnetic resonance imaging) appear to be diagnostic in $71 \%$ of the cases [9]. In our patient, only the ultrasound imaging was performed and it did not give a specific diagnosis. Surely the realization of magnetic resonance imaging could have helped us to characterize the lesion, but we were limited because the patient could not afford its expensive charge. Given the strong expression for CD34 in the immunohistochemical study, it confirmed for us the final diagnosis of spindle cell lipoma of the thumb. The treatment method for this tumor is marginal excision, together with the surrounding thin fibrous capsule [5].

\section{Conclusion}

Although lipomas of the digit are rare, they should always be kept in the list of the etiology of either painful or mechanic restricted motion of the digit. Besides, the spindle cell lipoma should be differentiated from the well-differentiated sclerosing liposarcoma and the spindle cell liposarcoma.

\section{Consent}

Consent of the patient was obtained.

\section{Conflicts of Interest}

The authors declare that they have no competing interests.

\section{References}

[1] V. D. Giorgi, C. Salvini, S. Sestini, B. Alfaioli, and P. Carli, "Lipoma of the finger: a case report and differential diagnosis," Clinical and Experimental Dermatology, vol. 30, no. 4, pp. 439440, 2005.

[2] C. D. M. Fletcher and E. Martin-Bates, "Spindle cell lipoma: a clinicopathological study with some original observations," Histopathology, vol. 11, no. 8, pp. 803-817, 1987.

[3] J. El Rayes, R. Bou Sader, and E. Saliba, "Lipoma of the thumb: spindle cell subtype," Case Reports in Orthopedics, vol. 2016, Article ID 9537175, 3 pages, 2016.

[4] A. Bhat, C. Vijaya, and S. B. Rao, "Pseudoangiomatous variant of spindle cell lipoma: report of a rare case," Indian Journal of Pathology and Microbiology., vol. 59, no. 3, p. 376, 2016.

[5] S. Ebisudani, I. Osugi, K. Inagawa, Y. Suzuki, and T. Kimura, "Spindle cell lipoma of the thumb," Plastic and Reconstructive Surgery - Global Open, vol. 6, no. 2, article e1671, 2018.

[6] F. M. Enzinger and D. A. Harvey, "Spindle cell lipoma," Cancer, vol. 36, no. 5, pp. 1852-1859, 1975.

[7] K. Akaike, Y. Suehara, T. Takagi et al., "Spindle cell lipoma of the wrist, occurring in a distinctly rare location: a case report with review of literature," International Journal of Clinical and Experimental Pathology, vol. 8, no. 3, pp. 3299-3303, 2015.

[8] C. Efstathios, N. Ptohis, K. Christos et al., "Patient presenting with lipoma of the index finger: a case report," Cases Journal, vol. 3, no. 1, article 20, 2010.

[9] M. D. Murphey, C. L. Andrews, D. J. Flemming, H. T. Temple, W. S. Smith, and J. G. Smirniotopoulos, "From the archives of the AFIP. Primary tumors of the spine: radiologic pathologic correlation," Radiographics, vol. 16, no. 5, pp. 1131-1158, 1996. 